\title{
Schottky enhancement of reacted NiAl/n-GaAs contacts
}

\author{
C.-P. Chen and Y. A. Chang \\ Department of Materials Science and Engineering, University of Wisconsin-Madison, 1509 University \\ Avenue, Madison, Wisconsin 53706 \\ T. F. Kuech \\ Department of Chemical Engineering, University of Wisconsin-Madison, 1415 Johnson Drive, Madison, \\ Wisconsin 53706
}

(Received 1 March 1994; accepted for publication 29 March 1994)

Schottky enhancement of reacted $\mathrm{NiAl} / n$-GaAs contacts was demonstrated experimentally. The Schottky barrier height increases from $0.83 \mathrm{eV}$ for the as-deposited contacts to $0.96 \mathrm{eV}$ when the contacts were annealed at $400^{\circ} \mathrm{C}$ for $1 \mathrm{~min}$. Formation of a high $\mathrm{Al}$ content ( $\mathrm{Al}, \mathrm{Ga}$ )As layer at the interface upon annealing was rationalized in terms of a thermodynamic/kinetic model. A (200) dark field cross-sectional transmission electron microscopy image was used to show the presence of high $\mathrm{Al}$ content $(\mathrm{Al}, \mathrm{Ga}) \mathrm{As}$ at the interface.

Understanding the mechanisms for the enhancement of Schottky barrier height (SBH) is not only scientifically but also technologically important. It can, for instance, be used to improve the current integrated circuit industrial process for fabricating electronic devices, i.e., metal-semiconductor field-effect transistors (MESFETs). A high SBH would allow a larger positive gate bias for enhancement mode MESFETs, thus permitting the fabrication of digital logic circuits with improved noise margins and a relaxed tolerance on device threshold voltage uniformity.

A number of schemes have been used to increase the SBH. Basically, these schemes can be classified into two categories. One category grows a thin layer of semiconductor, i.e., $\mathrm{Si}$, at the contact interface ${ }^{1}$ and the other category counter dopes the $n$-GaAs with a $p$-type dopant, i.e., $\mathrm{C}$ or $\mathrm{Zn}^{2}$ However, the contacts made using all these schemes suffer from poor thermal stability. Sands et al. ${ }^{3}$ showed that thermally stable contacts with higher SBH could be realized using the following contact structure: capped $\mathrm{Ni}(35 \mathrm{~nm}) /$ $\mathrm{Al}(68 \mathrm{~nm}) / \mathrm{Ni}(10 \mathrm{~nm}) / n$-GaAs. In their experiments, the layers were deposited by electron-beam evaporation. They obtained a value of $\mathrm{SBH}, \phi_{\mathrm{B} n}, \simeq 0.99 \mathrm{eV}$, after rapid thermal annealing of the fabricated layered structure at $650^{\circ}$ for $20 \mathrm{~s}$. The SBH was obtained from the current-voltage method. Subsequently, Chambers ${ }^{4}$ grew a layer of $\mathrm{NiAl}$ on a substrate of $n$-GaAs at a substrate temperature of $500{ }^{\circ} \mathrm{C}$ using molecular-beam epitaxy (MBE). He obtained a value of $\phi_{B n} \approx 0.9 \mathrm{eV}$ using x-ray photoemission spectroscopy. Neither of these studies attempted to describe the cause of this Schottky barrier enhancement. However, both Sands et al. ${ }^{3}$ and Chambers ${ }^{4}$ speculated that the Schottky barrier enhancement was due to the exchange of $\mathrm{Al}$ and $\mathrm{Ga}$ at the interface, resulting in the formation of a thin $(\mathrm{Al}, \mathrm{Ga}) \mathrm{As}$ layer. Nevertheless, there was no definitive experimental evidence to show the existence of such an $(\mathrm{Al}, \mathrm{Ga})$ As layer. Moreover, Chen et al..$^{5}$ showed recently that the Schottky enhancement of a layered structure of $\mathrm{Ni} / \mathrm{Al} / \mathrm{Ni} / n-\mathrm{GaAs}$, upon annealing, can be attributed to a regrowth mechanism and not due to the exchange of $\mathrm{Al}$ and $\mathrm{Ga}$ at the interface.

The objectives of the present study are to (i) deposit films of NiAl on a substrate of $n$-GaAs using a sputter depo- sition method, (ii) determine the Schottky barrier height of the $\mathrm{NiAl} / n-\mathrm{GaAs}$ contacts as a function of rapid thermal annealing temperature using the current-voltage $(I-V)$ method, (iii) propose a mechanism to rationalize the formation of $(\mathrm{Al}, \mathrm{Ga}) \mathrm{As}$ at the metal/semiconductor interface which is responsible for the Schottky enhancement, and (iv) establish experimentally the existence of this phase.

Unintentionally doped $\left(\sim 3 \times 10^{16} \mathrm{~cm}^{-3}\right) n$-GaAs wafers with a (100) orientation were used as substrates in the present study. A standard photolithographic lift-off process was used for fabricating the contacts. The substrates were degreased with trichlorethylene, acetone, and methanol for 5 min each. The degreased wafers were then patterned with an array of $0.5 \mathrm{~mm}$ diameter dots using a standard lithographic technique. Prior to metal deposition, the patterned substrates were cleaned for $2 \mathrm{~min}$ by $\mathrm{NH}_{4} \mathrm{OH}: \mathrm{H}_{2} \mathrm{O}(1: 2)$, followed by blow drying with $\mathrm{N}_{2}$. Films of NiAl were deposited hy sputter deposition to a thickness of $100 \mathrm{~nm}$ at an Ar pressure of $4 \mathrm{~m}$ Torr. The concentration of a $2 \mu \mathrm{m}$ thick NiAl film sputter deposited on a glass plate under identical conditions was determined by EPMA to be $50 \pm 0.3$ at. \% Al. Annealing was carried out in a rapid thermal annealing furnace in an $\mathrm{Ar}$ ambient at $325^{\circ} \mathrm{C}$ for $5 \mathrm{~min}, 400{ }^{\circ} \mathrm{C}$ for $1 \mathrm{~min}, 500^{\circ} \mathrm{C}$ for $20 \mathrm{~s}$, and $600{ }^{\circ} \mathrm{C}$ for $20 \mathrm{~s}$. The backside ohmic contacts were formed by alloying In onto the $n$-GaAs substrate at a temperature of $400^{\circ} \mathrm{C}$ for $1 \mathrm{~min}$. The ohmic contacts were made prior to the Schottky metallization for samples annealed below $400^{\circ} \mathrm{C}$ and after metallization for samples annealed above $400^{\circ} \mathrm{C}$.

The electrical measurements were made at room temperature. The current-voltage $(I-V)$ measurements were performed with a Keithley model 236 electrometer. The $I-V$ characteristics were analyzed using the conventional thermionic-emission theory. ${ }^{6}$ The relationship between the current and the applied forward voltage is given by the following equation:

$$
\begin{aligned}
I= & S A^{* *} I^{2} \exp \left[-q\left(\phi_{B n}-\Delta \phi_{B n}\right) / k_{B} T\right] \\
& \times\left[\exp \left(q V / n k_{B} T\right)-1\right],
\end{aligned}
$$

where $S$ is the contact area, $A^{* *}$ is the effective Richardson 


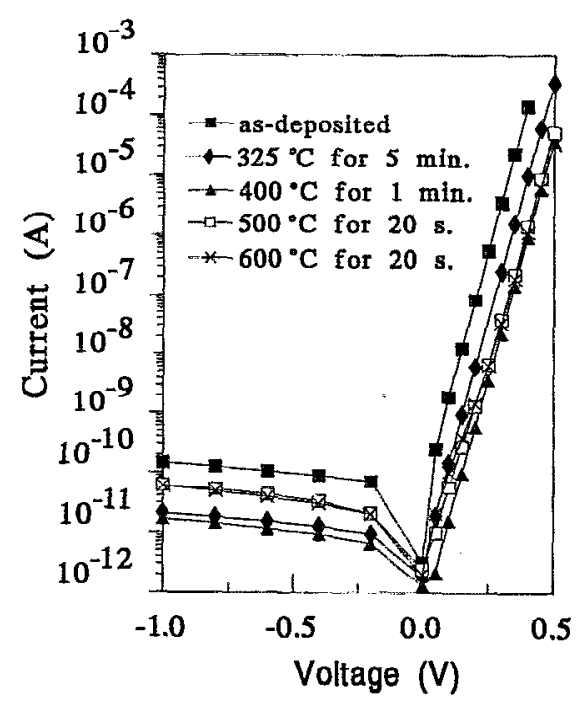

FIG. 1. The $I-V$ characteristics of the NiAl $/ n$-GaAs contacts are shown for contacts after different thermal treatments. A linear relationships was found in the $\log I-V$ characteristics under forward bias, over a wide range of the current measured, i.e., six orders of magnitude.

constant (8.64 A/cm ${ }^{2} \mathrm{~K}^{2}$ for $n$-GaAs), $k_{B}$ is the Boltzmann constant, $T$ is the temperature in $K, \phi_{B n}$ is the Schottky barrier height, $\Delta \phi_{B n}$ is the Schottky barrier lowering [(equal to $\left.\left.\left(q E / 4 \pi \varepsilon_{s}\right)^{1 / 2}\right)^{6}\right], E$ is the maximum electric field at the metal-semiconductor interface, $\varepsilon_{s}$ is the permittivity of the semiconductor, and $n$ is the ideality factor. The ideality factor must be close to unity in order to assure that thermionic emission is the dominant transport mechanism.

Transmission electron microscopy (TEM) examination of the reacted interfaces was carried out using a JEOL 200 CX.

The experimental $I-V$ data presented in Fig. 1 shows the existence of a linear region in a semilog plot of forward bias over six orders of magnitude for the applied voltage. The leakage current is below $1 \times 10^{-7} \mathrm{~A} / \mathrm{cm}^{2}$ at a reverse bias of $1 \mathrm{~V}$ for all the contacts. Values of the SBH, $\phi_{B n}$, as well as the ideality factors, $n$, are summarized in Table $\mathrm{I}$ as a function of annealing temperature. The data clearly indicate that the Schottky behavior of the uncapped NiAl $/ n$-GaAs contacts follows the thermionic-emission model. Ideality factors, equal to or less than 1.1, were determined on structures after annealing at temperatures as high as $600^{\circ} \mathrm{C}$ for $20 \mathrm{~s}$. The contacts, which become nonrectifying after being annealed at $650^{\circ} \mathrm{C}$ for $20 \mathrm{~s}$, are not listed in Table I. The maximum barrier height of the uncapped contact, $0.96 \mathrm{eV}$, is close to that of the capped $\mathrm{Ni} / \mathrm{Al} / \mathrm{Ni} / n-\mathrm{GaAs}$ contact, $0.99 \mathrm{eV}$, annealed at $650^{\circ} \mathrm{C}$ for $20 \mathrm{~s}$ obtained by Sands et al. ${ }^{3}$ It is higher than that of the $\mathrm{NiAl} / n$-GaAs contacts, $0.9 \mathrm{eV}$, grown by MBE at $500^{\circ} \mathrm{C}$ by Chamber. ${ }^{4}$ Chamber's Schottky barrier height was derived from a different experimental method which may account for the $0.06 \mathrm{eV}$ difference between his result and the value reported here.

The processing used in the present study offers several practical advantages over those used by Sands et al. ${ }^{3}$ and Chambers. ${ }^{4}$ Sands et al. had to use an AlN cap as well as
TABLE I. Schottky barrier heights and the ideality factors obtained for the reacted $\mathrm{NiAl} / n$-GaAs contacts using the $I-V$ method.

\begin{tabular}{ccc}
\hline Heat treatments & $\phi_{B_{H}}$ & $n$ \\
\hline As-deposited & 0.83 & 1.03 \\
$325^{\circ} \mathrm{C} / 5 \mathrm{~min}$ & 0.90 & 1.05 \\
$400^{\circ} \mathrm{C} / 1 \mathrm{~min}$ & 0.96 & 1.06 \\
$500^{\circ} \mathrm{C} / 20 \mathrm{~s}$ & 0.94 & 1.09 \\
$600^{\circ} \mathrm{C} / 20 \mathrm{~s}$ & 0.89 & 1.14 \\
\hline
\end{tabular}

anneal their contacts at $650{ }^{\circ} \mathrm{C}$ to achieve Schottky barrier enhancement. In the present study, only a short anneal of the contacts at $400{ }^{\circ} \mathrm{C}$ for $1 \mathrm{~min}$ was necessary. This makes our processing technique compatible with the use of an $\mathrm{Au}-\mathrm{Ni}-\mathrm{Ge}$ ohmic contact. It is known that the $\mathrm{Au}-\mathrm{Ni}-\mathrm{Ge}$ contacts to $n$-GaAs requires annealing at $400{ }^{\circ} \mathrm{C}^{7}$ to achieve a low contact resistivity. Secondly, sputter deposition can be adopted for most practical applications, eliminating the need for a MBE-based technology.

We will use the thermodynamic and kinetic analysis proposed by $\mathrm{Jan}^{8}$ to rationalize the formation of $(\mathrm{Ga}, \mathrm{Al}) \mathrm{As}$ at the metal/semiconductor interface which is responsible for the Schottky enhancement of the NiAl $/ n$-GaAs contacts. The analysis proposed by $\operatorname{Jan}^{8}$ was recently summarized by Chang."

This analysis is applicable for the reciprocal system of $\mathrm{NiGa}-\mathrm{NiAl}-\mathrm{AlAs}-\mathrm{GaAs}$ that exists in the quaternary $\mathrm{Ga}-\mathrm{Ni}-\mathrm{Al}-\mathrm{As}$ system. The phase diagram of such a reciprocal system is given in Fig. 2. As shown in this figure, a two-phase equilibrium exists between the $\mathrm{Ni}(\mathrm{Ga}, \mathrm{Al})$ phase denoted as $\beta$ and the $(\mathrm{Ga}, \mathrm{Al})$ As phase denoted as $\alpha$. This diagram was determined experimentally at $800^{\circ} \mathrm{C}$ by Jan. ${ }^{8}$ The dashed lines which connect the compositions of the coexisting $\alpha$ and $\beta$ phases are referred to as the tie lines. Even though the diagram was determined at $800^{\circ} \mathrm{C}$, the phase diagrams at any other temperature may be calculated thermodynamically. ${ }^{9}$ The calculated diagram at $800{ }^{\circ} \mathrm{C}$ is in agreement with the experimentally determined diagram.

It is clear from Fig. 2 that thermodynamic equilibrium does not exist at the $\mathrm{NiAl} / n$-GaAs interface. Interfacial reaction will occur. Assuming diffusion to be the rate limiting

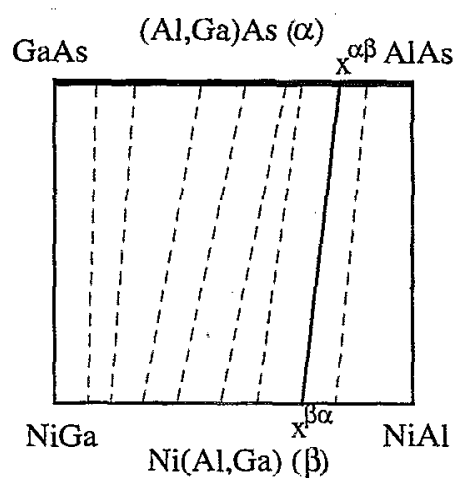

FIG. 2. The experimentally determined tie lincs in a phase diagram of the $\mathrm{GaAs}-\mathrm{NiGa}-\mathrm{NiAl}-\mathrm{AlAs}$ system at $800^{\circ} \mathrm{C}$ were reported by Jan (see Ref. 8). 


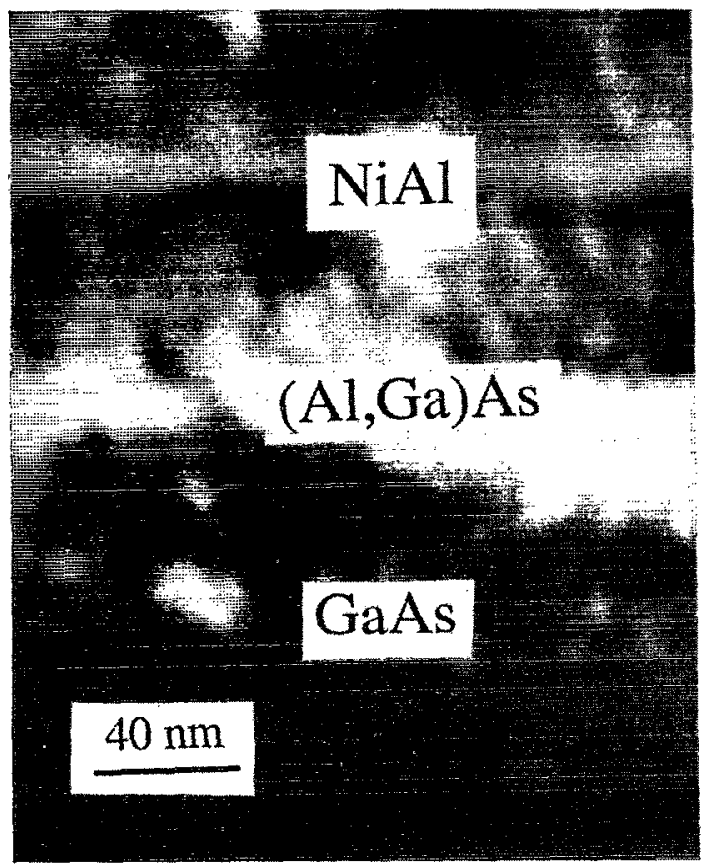

FIG. 3. (200) dark field XTEM images of the contact annealed at $700{ }^{\circ} \mathrm{C}$ for $20 \mathrm{~s}$ is used to determine the presence of $\mathrm{a}(\mathrm{Al}, \mathrm{Ga}) \mathrm{As}$ phase. The $(\mathrm{Al}, \mathrm{Ga}) \mathrm{As}$ phase would be bright and the GaAs phase would be dark on the (200) dark field image.

step, the compositions of the coexisting phases at the metal/ semiconductor interface is related to the interdiffusion coefficients of the $\alpha$ and $\beta$ phases, as given by

$$
\frac{x^{\alpha \beta}}{1-x^{\beta \alpha}}=\sqrt{\frac{\tilde{D}^{\beta}}{\tilde{D}^{\alpha}}}
$$

where $x^{\alpha \beta}$ is the concentration of AlAs in the $\beta$ phase at the $\alpha / \beta$ interfaces, $x^{\beta \alpha}$ is that of NiAl in the $\alpha$ phase at the $\alpha / \beta$ interface, $\tilde{D}^{\beta}$ is the interdiffusion coefficient of the $\beta$ phase, and $\tilde{D}^{\alpha}$ is that of the $\alpha$ phase. Other assumptions involved in obtaining Eq. (2) are that the interdiffusion coefficients are composition independent and that the $\alpha / \beta$ interface is stationary. Values of $x^{\alpha \beta}$ and $x^{\beta \alpha}$ are the compositions of the $\alpha$ and $\beta$ phases for a specific tie line, as shown in Fig. 2. The dark line shown in this figure is termed a diffusion path. The diffusion path states graphically that the concentration at the $\alpha / \beta$ interface is $x^{\alpha \beta}$ and $x^{\beta \alpha}$. The AlAs concentration in the $\alpha$ phase decreases from $x^{\alpha \beta}$ at the interface to zero far away from the interface, i.e., the bulk GaAs substrate. The NiAl concentration in the $\beta$ phase, in a similar manner, increases from $x^{\beta \alpha}$ at the interface to 1 , i.e., the bulk NiAl phase.

It is evident from Eq. (2) that if we know the values of $\tilde{D}^{\alpha}$ and $\tilde{D}^{\beta}$, we can readily calculate the concentrations of (Al,Ga)As and $\mathrm{Ni}(\mathrm{Al}, \mathrm{Ga})$ at the $\mathrm{NiAl} / n-\mathrm{GaAs}$ interface. Since $\tilde{D}^{\beta}$ is several orders of magnitude larger than $\tilde{D}^{\alpha},{ }^{10,11}$ the value of $x^{\alpha \beta}$ at the reacted $\mathrm{NiAl} / n-\mathrm{GaAs}$ interface at
$400{ }^{\circ} \mathrm{C}$ would be close to 1.0 , i.e., the $(\mathrm{Al}, \mathrm{Ga})$ As formed at the interface is close to pure AlAs. In view of the fact that the Schottky barrier height to $n$-AlAl is $\sim 1.0 \mathrm{eV},{ }^{12}$ a reacted $\mathrm{NiAl} / n$-GaAs contact at $400^{\circ} \mathrm{C}$ would exhibit a Schottky barrier enhancement.

The presence of $(\mathrm{Ga}, \mathrm{Al}) \mathrm{As}$ at the interface was demonstrated using a (200) dark field XTEM image. ${ }^{13}$ The difference between the atomic scattering factor of $\mathrm{Al}$ and that of As is significant, while the atomic scattering factors of $\mathrm{Ga}$ and $\mathrm{Al}$ are quite similar. Therefore, the $(\mathrm{Al}, \mathrm{Ga}) \mathrm{As}$ phase would appear bright while the (Ga,As) phase would appear dark in the dark field image. A (200) dark field XTEM image of the $\mathrm{NiAl} / n$-GaAs contacts annealed at $700^{\circ} \mathrm{C}$ for $20 \mathrm{~s}$ are shown in Fig. 3. Figure 3 shows a bright thin layer formed at the interface, which is presumed to be the high $\mathrm{Al}$ content (Al,Ga)As phase. It is the presence of this phase which results in the Schottky barrier enhancement.

In summary, thermally stable $\mathrm{NiAl} / n$-GaAs Schottky contacts, up to $600{ }^{\circ} \mathrm{C}$ for $20 \mathrm{~s}$, have been realized. The contacts were made by sputter deposition from a $\mathrm{NiAl}$ target to substrates of (100) $n$-GaAs at a base pressure $\sim 2 \times 10^{-7}$ Torr. The high Schottky barrier height $0.96 \mathrm{eV}$ with an ideality factor of 1.1 deduced from the $I-V$ was measured for the contacts annealed at $400{ }^{\circ} \mathrm{C}$ for $1 \mathrm{~min}$. The Schottky barrier enhancement is rationalized in terms of a thermodynamic/kinetic model for interfacial reactions within the reciprocal system of $\mathrm{NiGa}-\mathrm{NiAl}-\mathrm{AlAs}-\mathrm{GaAs}$ that exists in the quaternary $\mathrm{Ga}-\mathrm{Ni}-\mathrm{Al}-\mathrm{As}$ system. It is the presence of the AlGaAs aphase which results in the Schottky barrier enhancement. The existence of this phase at the reacted interface was verified using a (200) dark field XTEM image of a contact annealed at $700{ }^{\circ} \mathrm{C}$ for $20 \mathrm{~s}$.

The authors wish to thank Dr. M. Dahms of GKSS, Geesthacht, Germany for making the NiAl sputtering target for us. The authors also wish to thank D. Swenson for reviewing this manuscript. The financial support of the Department of Energy through Grant No. DE-FG02-86ER452754 is gratefully acknowledged.

${ }^{1}$ J. R. Waldrop and R. W. Grant, Appl. Phys. Lett. 52, 1794 (1988).

${ }^{2}$ S. J. Pearton, F. Ren, C. R. Abernathy, W. S. Hobson, S. N. G. Chu, and J. Kovalchick, Appl. Phys. Lett. 55, 1342 (1989).

${ }^{3}$ T. Sands, W. K. Chan, C. C. Chang, E. W. Chase, and V. G. Keramidas, Appl. Phys. Lett. 52, 1338 (1988).

${ }^{4}$ S. A. Chambers, J. Vac. Sci. Technol. B 7, 737 (1989).

${ }^{5}$ C.-P. Chen, Y. A. Chang, and T. F. Kuech, J. Vac. Sci. Technol. (in press).

${ }^{6}$ S. M. Sze, in Physics of Semiconductor Devices (Wiley, New York, 1981).

${ }^{7}$ C. Lin and C. P. Lee, J. Appl. Phys. 67, 260 (1990).

${ }^{8}$ C.-H. Jan, Ph.D. Thesis, University of Wisconsin, Madison 1991.

${ }^{9}$ Y. A. Chang, Mat. Res. Symp. Proc. 260, 43 (1992).

${ }^{10}$ L. Harrison, J. Mater. Sci. 4, I (1993).

${ }^{11}$ S. Shankar and L. L. Seigle, Met. Trans. 9A, 1467 (1978).

${ }^{12}$ T. L. Cheeks, T. Sands, R. E. Nahory, J. P. Harbison, H. L. Gilchrist, and V. G. Keramidas, J. Electron. Mater. 20, 881 (1991).

${ }^{13}$ T. S. Huang, J. G. Peng, and C. C. Lin, J. Vac. Sci. Technol. B 11, 756 (1993). 